\title{
Library Internet Use and Demographic Characteristics of Undergraduates in a Nigerian University: Uncovering the Areas of Need.
}

\author{
Emezie, Nkeiru. A. ; Chukwu, Scholastica .A.J. ; Onyebinama, Colette, O. ; Chima-James, Ngozi \& Nwaohiri, \\ Ngozi. M \\ The Library, Federal University of Technology Owerri, Nigeria. \\ Corresponding author nnechika2005@gmail.com
}

\begin{abstract}
This study investigated undergraduates of Federal University of Technology Owerri, Nigeria to ascertain whether their demographic profile was a characteristic of library internet usage. Data used for the study was a textual analysis of statistic register on library internet use from May 2017 - June 2018. The study population consisted of 2682 valid name entries during the period under study. Findings revealed that FUTO has greater number of male undergraduates and this is due to the academic structure of the institution. Discipline wise demographic characteristics showed that undergraduates from Agricultural Economics made most use of the library internet in School of Agriculture and Agricultural Technology (SAAT) while those in department of Electrical and Electronics Engineering (EEE) were the most users in School of Engineering and Engineering Technology (SEET). Also, undergraduates from Information Management Technology (IMT) and Project Management Technology (PMT) used the internet most in School of Management Technology (SMAT) while those in Biotechnology (BIO) were the most users in School of Biological Sciences (SOBS). Further findings revealed that undergraduates from Surveying and Geoinformatics (SVG) were the most library internet users in School of Environmental Technology (SOET) while Biomedical Technology undergraduates (BMT) made use of the internet more than their counterparts in the School of Health Technology (SOHT). Similarly, Computer Science (CSC) students used the internet most in School of Physical Sciences (SOPS). On the overall faculty level, School of Engineering and Engineering Technology (SEET) made most use of the library internet than other Schools. In terms of study level, it was revealed that final year (500 level) students used the library internet most. Having uncovered the disparity in library internet use, the study recommends among others that embedded librarians in FUTO should promote library operations and services through constant connection and communication with their various departments, continuous marketing and awareness creation of the library's internet facility.
\end{abstract}

Keywords: Academic library, Internet, Demographic characteristics, FUTO, Undergraduates, Nigerian University, Schools.

DOI: $10.7176 / \mathrm{IKM} / 10-2-08$

Publication date: March $31^{\text {st }} 2020$

\section{Introduction}

The use of internet has become a vital part of undergraduate students' academic life in the current electronic information environment. As a result, internet usage is common place in higher institutions of learning. Students resort to internet for various purposes such as assignments, term/seminar papers and even e-learning especially on Youtube channels. That is why Ugwulebo and Okoro (2016) posit that the internet is a relatively new channel for scholarly resources and contain vast quantities of information. The shift in use of internet as an academic resource is consequent upon the networked environment that is saturated with electronic mobile devices. Thus, smart phones, tablets and laptops are easily used to access the internet from various locations. With smart phones for instance, students can download various apps that enable faster access to the internet for academic or entertainment purposes. Accordingly, these shifts in information access and use has had negative impacts on libraries which are the hub of information provision in higher institutions.

However, university libraries whose major aim is to support teaching and learning have keyed into this paradigm in order to remain vital and responsive to the needs of users. Changes in information need and seeking behavior of undergraduate students has resulted in changing library practices and services. One significant change is the deployment of internet facilities in many university libraries. Nowadays, libraries are providing internet to complement traditional services as well as keep track of new developments. To align with user needs, databases, 
e-books, e-journals and other electronic resources are now part of the library's collections. These electronic resources are either accessed offline or real time via internet which has the potential of speed and quick access. Of the many innovative strategies employed by libraries in the $21^{\text {st }}$ century, the internet appears to have an overwhelming impact in that it provides anchorage for libraries in the technology surge. Thus, the use of internet as an academic resource in university libraries has become extremely important.

The place of internet in the provision of information cannot be overemphasized. Internet has been identified as key tool for enhancing library services. This is because internet enables multiple and simultaneous access to electronic information resources thus reducing the tension and uncertainty of cueing for a single document which may never be available at the time of need. Brown and Adler (2008) provide that the internet has the features of accuracy, comprehensiveness and is time saving. Topaloglu and Topaloglu (2014) maintain that the Internet is a budget friendly resource providing infinite information, it is one of the most important means of information technology which offers richness and ease. In the same vein, Korobili, Tiikidrou and Delistavrou (2006) in citing Barllan et al (2003) identified that speed, accessibility and searchability were the main advantages of using the internet. Another advantage as identified by Kilic and Guzeller (2017) is the variety of knowledge presentation or the speed and convenience of information access. Furthermore, the authors emphasized that internet is one of the most important tools enabling enhancement of the digital natives' learning capacity.

Undergraduate students in the present dispensation fall within the category of human race termed as digital natives. This is because they are born in an age of technology. Their information seeking patterns are different in that they are comfortable with using computers and technology as tools for learning. Their assimilation is greater with interactive learning as opposed to passive learning methods. Cabero-Johnson and Barge (2009) in citing Prensky (2001) opine that "digital natives are savvy in the use of email, instant messaging, internet, and text messaging. They are different than any other generation because technology is an integral part of their lives. They live, breathe, work, and play with the tools and products of the digital age and they employ these tools quite uniquely".

From the foregoing, digital natives are at home with technology and prefer to "google it" rather than search for resources in the library. The above statement attributes the undergraduates who use internet to a large extent for various purposes. That is why Owolabi (2013) assert that they appear more technology enthusiast and most often are too busy to experiment with new technology innovations, the younger age group are more technology savvy and can easily contend with the challenges and complexities of the innovation. Talwar et al (2018) also point that most of the younger generation, especially college-aged students, have grown up in the internet era and have never lived in a world without the internet. Despite their unflinching penchant for information and communication technologies, undergraduates' use of internet may vary due to certain demographic characteristics such as age, gender, discipline and level of study.

Undergraduates in the Federal University of Technology Owerri consists of male and female students with different age, backgrounds, creed and ethnicity who have satisfied the requirements for entrance into Nigerian higher institutions and are duly admitted into various programmes run by the institution. In their quest for excellence, they use the library resources and internet to support and complement academic work. Students enjoy free access to the internet once they are registered with the library and have a valid library card. Undergraduate students in FUTO are constantly encouraged to avail themselves of the opportunities provided by the library internet to key into the electronic information environment. As a result the management ensures that library internet is up and running to continuously provide support for academic activities in the university.

\section{Literature Review}

Several studies have identified various demographic characteristics which determine internet use. Among these are Ajuwon and Popoola (2014) who stated that age is a characteristic that have been found to play a substantial role in influencing internet usage. According to the authors, youths tend to be more comfortable with using computer and the internet than adults. Quadri (2013) states that younger users rely on electronic resources more heavily and rate themselves more expert in using them than older users. From empirical perspective, Okiki (2011) found that there were significant age differences on the computer task, younger adults make quick decisions with the aid of computers compared to the older adults that make few correct decisions taking longer time than younger adults. Anunobi and Mbagwu (2009) in their study reveal that the younger adults (15 - 30) constitutes $73.97 \%$ of internet users in Imo state. Stone and Collins (2013) also found that undergraduates within the age of 21 and above used the internet to a large extent. A recent survey carried out by Pew Research Center earlier in 2018 on US internet usage by age group, found that 98 percent of 18 to 29-year olds in the United 
States were internet users. This consolidates the evidence that younger people mostly within the age bracket of undergraduates were most users of the internet.

Gender has also been identified as a determinant factor in internet use. Selwyn (2008) reported that gender and course affected use of the Internet. Tchombe (2008) opine that ICT especially in developing African countries, is an area quite sensitive to gender where women and girls are at particular risk of exclusion from potential opportunities for various reasons. Relating to sex of internet users, Anunobi and Mbagwu (2009) found that more male children and male younger adults use internet than their female counterparts. Jones, Johnson-Yale, Millermaier, and Pérez (2009) found that male college students spent more time online than female students. Another study by Okwaraji, et. al. (2015) indicate that male undergraduate students reported higher internet addiction than their female counterparts. Similarly, Ajuwon and Popoola (2014) assert that males are more internet savvy than females. Servidio (2014) demonstrated in his findings that males were more inclined to use the Internet than females. Furthermore, Adepoju (2017) found a significant difference in the utilisation of ICT between male and female students. This meant that male students made use of ICT more than the females.

However, it has been reported that the gender gap in the use of the Internet has been narrowing in recent years (Wong et al, 2008; Odell et al, 2000). Contrary to these, Cox and Jantti (2012) reported that there were gender differences in library electronic resource usage, finding that women used e-resources more than men. Stone and Graham (2013) in their study of undergraduates in UK found that women showed higher usage than men on all the dimensions to do with use of electronic library resources while Castano, Duart and Vinuesa (2015) observe that women are the gender that use the Internet most for interactive learning more than men from this same university. Subsequently, Kilic and Guzeller (2017) showed in their study that female used the internet more than males for doing homework. The studies above however agree on common grounds that females used the internet more for their academic work while males were more concerned with browsing for leisure and other online activities.

In terms of discipline of study, Okiki and Asiru (2011) were of the opinion that the factors that influence the use of Electronic information sources among students varied according to the program of their study. This means that a student's course or type of discipline is determinant on his/her internet usage. Indications from the study by Stone and Collins (2013) reveal that discipline exerts a much bigger influence on internet usage. Ngoumandjoka (2012) corroborates this assertion in his finding that science students consume more Internet bandwidth than students from other disciplines. Also, Dery (2016) found that the Dental School had the highest proportion of respondents who used internet more than others in the college of health sciences in University of Ghana. Castano, Duart and Vinuesa (2015) observe that having high internet usage abilities has a different effect according to the study program in which the student is pursuing his/her degree. To buttress this, the authors state that humanities students and the students in the 2nd-term of the virtual program have higher internet usage. Hussain and Rammah (2017) also show that the percentage of internet usage among the students coming from Business Studies was higher than those from Science and Arts background at the University of Dhaka. Based on the findings, a similar study is needful in FUTO to ascertain if discipline is a characteristic of library internet usage.

Level of study has also been recognized to influence internet use by undergraduates. Quadri (2013) in his study of two Nigerian universities found a strong relationship between the level of study and utilization of online library resources by the university undergraduate students. This was corroborated by Okwaraji, et al. (2015) who showed that final year undergraduate students reported more severe internet addiction than those at other levels. Bolu-Steve, Oyeyemi, and Amali (2015) found a significant difference in use of internet and educational levels of University of llorin undergraduates students. It can be inferred from the above that the higher the level of undergraduates, the greater their ability to use internet sources for research. Bidin, Shamsudin, Sharrif and Hashim (2011) corroborates this assertion when they reasoned that final year business students were chosen to participate in their study because they have been exposed to the higher education environment for quite some time and hence are better exposed to the internet applications in their academic experiences. Conversely, Chaudhauri et al (2015) in their study of medical undergraduate students found that year of study did not have significant association with internet addiction. Ineme, Ineme, Akpabio and Osinowo (2017) validates the above finding in reporting that final year and the non-final year students were not significantly different in their levels of internet addiction; the authors maintained that any difference found in the level of Internet addiction could not be attributed to the year of study.

Literature has revealed plethora of studies on internet use and demographic characteristics of undergraduates. Some of these studies established that demographic profile has effect on undergraduates' use of internet. While 
several of these studies have been carried out in Nigeria and beyond, there has been no study known to the researchers on library internet use and demographic characteristics of undergraduates in Federal University of Technology Owerri Nigeria. Hence a study of this nature in FUTO library is imperative to determine the gaps that exist in internet usage and further provide possible suggestions that would promote optimal use of the internet facilities so provided. As a result, this study is situated to identify the demographic characteristics of undergraduates as it relates to library internet usage in terms of gender, discipline and level of study.

\section{Objectives}

1. Ascertain if gender is a characteristic of library internet usage in FUTO

2. Identify if discipline of study is a characteristic of library internet usage in FUTO

3. Find out if level of study is a characteristic of library internet usage in FUTO

4. Ascertain if any gaps exist in undergraduates demographic characteristics and provide possible recommendations.

\section{Method}

The qualitative research involves a textual analysis of statistic register on library internet use from May 2017 June 2018. This period was chosen because the new e-library was opened to students in May 2017 and so far, the library has recorded greater influx of students due to improved internet access. Valid entries derived from the register consists of 2682 names of students. To extract data for analysis, names of students found in the statistics record were listed in alphabetical sequence. In so doing, names with multiple entries were captured only once. The aim was to avoid repetitive entries. In order to determine the demographic profile of students using their name entries, the researchers classified each entry according to gender, department and level of study. The departments were further grouped into various schools to ascertain discipline wise demographic analysis of undergraduates' internet usage. An overall analysis of the Schools was carried out to equally determine the faculty with the highest internet usage. Data extracted from the statistics register was analyzed using descriptive statistics such as charts, percentages and frequency counts.

\section{Result}

The demographic characteristics of undergraduate students in terms of gender is shown in the diagram below

\subsection{Gender Distribution}

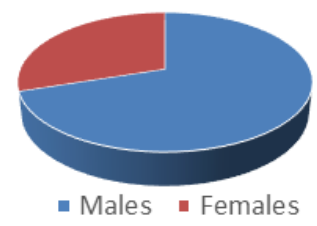

Figure 1: Demographic characteristics in terms of gender

Figure 1 shows the data distribution on gender. Out of the 2682 entries of students names that were deemed valid for this study, 1869 were males whereas $803(30 \%)$ were females. This is unsurprising as the academic structure of FUTO hinges on science and technology. Given this fact, males are likely to hold the greater population as a result of the gender stereotype on courses offered in the institution. 


\subsection{Analysis Of Demographic Characteristics Of Undergraduates In Terms Of Discipline}

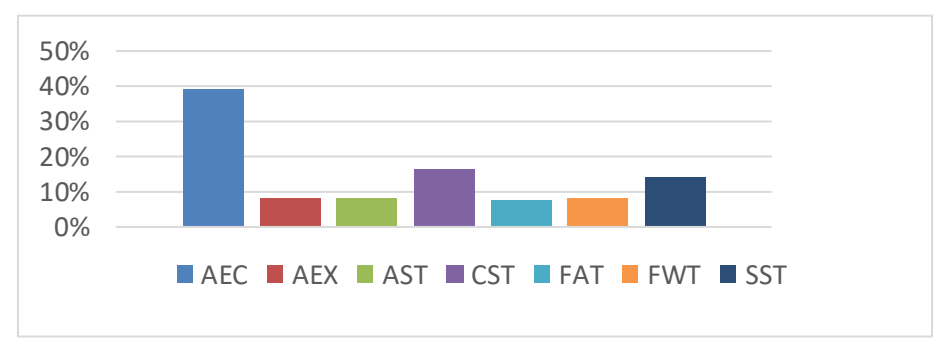

Figure 2: Discipline wise demographic analysis of undergraduates from School Of Agriculture And Agricultural Technology

Figure 2 shows results of analysis of library internet usage of undergraduate students from School of Agriculture and Agricultural Technology (SAAT). Out of the 232 names from SAAT, students from Agricultural Economics (AEC) made most use of the library internet 90 (39\%), this was followed by Crop Science Technology 35(16\%) while 32 (14\%) were from Soil Science Technology. Other students from Agricultural Extension, Animal Science Technology, Forestry and wildlife recorded $20(8 \%)$ each whereas $15(7 \%)$ were from undergraduates from department of Fishery and Aquaculture Technology.

\subsection{School Of Engineering and Engineering Technology (SEET)}

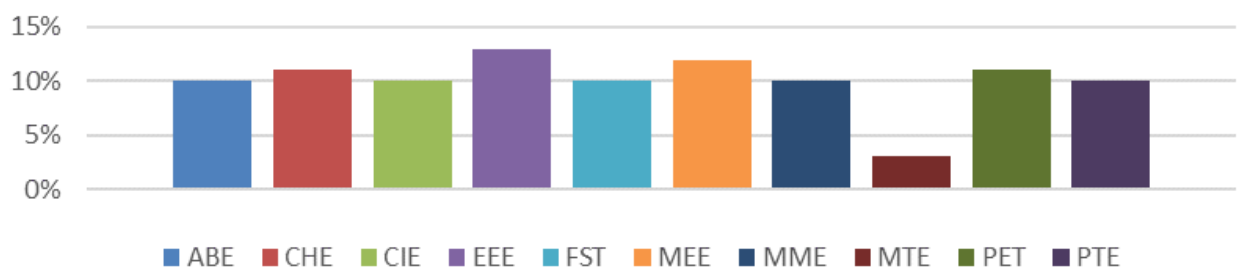

Figure 3: Discipline wise demographic analysis of undergraduates from School of Engineering And Engineering Technology

Figure 3 above shows analyses of data on library internet usage of undergraduates from School of Engineering and Engineering Technology. Data analysis reveal that out of the ten departments which make up this School, $123(13 \%)$ of students from the department of Electrical and Electronics Engineering (EEE) made most use of the library internet. This was followed by 118 (12\%) students from Mechanical Engineering (MEE). Also 104(11\%) students from Chemical Engineering (CHE) and 100(11\%) from Petroleum Engineering (PET) made use of the library internet. Further analyses from other departments showed that Agricultural and Biosciences Engineering (ABE), Polymer and Textile Engineering (PTE), Materials and Metallurgical Engineering (MME), Food Science and Technology (FST), and Civil Engineering (CIE) had 97, 97, 95, 92 and 90 entries representing approximately 10\% each. However, students from Mechatronics Engineering (MTE) had the lowest usage with $24(3 \%)$ entries. 


\subsection{School Of Management Technology (SMAT)}

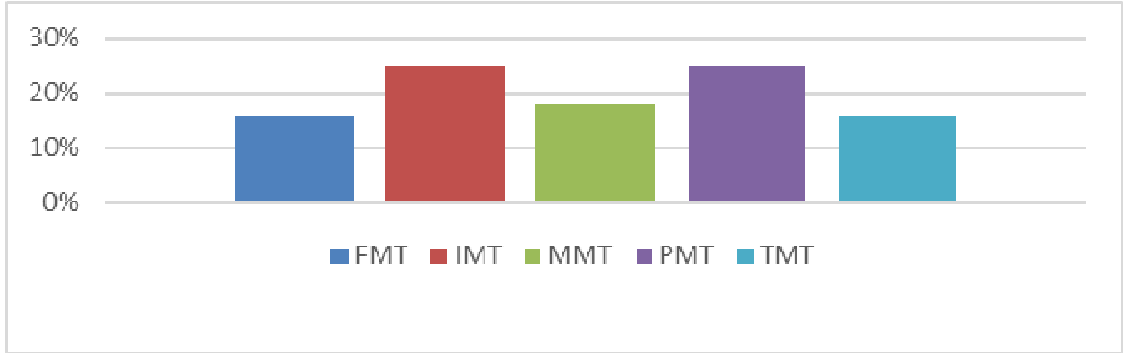

Figure 4: Discipline wise demographic analysis of undergraduates from School of Management Technology (SMAT)

Analysis from Figure 4 above shows that in the School of Management Technology (SMAT), undergraduate students from Department of Information Management Technology (IMT) and Project Management Technology (PMT) recorded $60(25 \%)$ entries in library internet usage respectively while department of Maritime Management Technology (MMT) recorded 42 (18\%). This was closely followed by Financial Management Technology (FMT) and Transport Management Technology (TMT) which had 16\% representing 38 and 39 entries respectively.

\subsection{School of Biological Sciences (SOBS)}

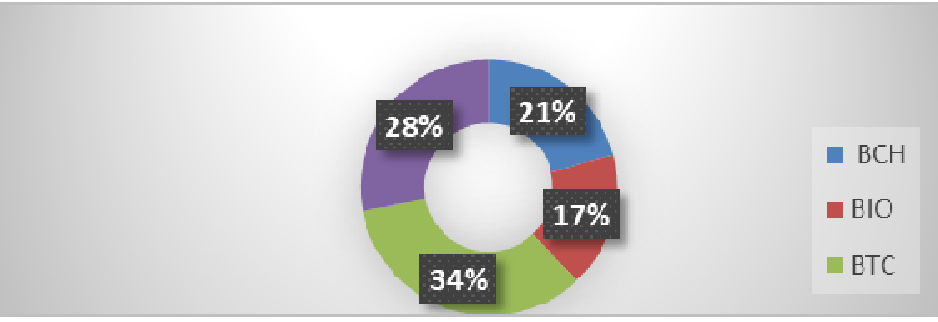

Figure 5: Discipline wise demographic analysis of undergraduates from School of Biological Sciences (SOBS)

From Figure 5 above, the School of Biological Sciences consists of four departments. Analysis reveal that undergraduates from the Department of Biotechnology (BIO) made the most use of the library internet during the reporting period 88(34\%), followed by Microbiology (MCB) which recorded $72(28 \%)$ entries. Further analysis reveal that $55(21 \%)$ of undergraduates from the Department of Biochemistry $(\mathrm{BCH})$ used the internet while 44(17\%) were from Biological Sciences (BIO).

\subsection{School of Environmental Technology (SOET)}

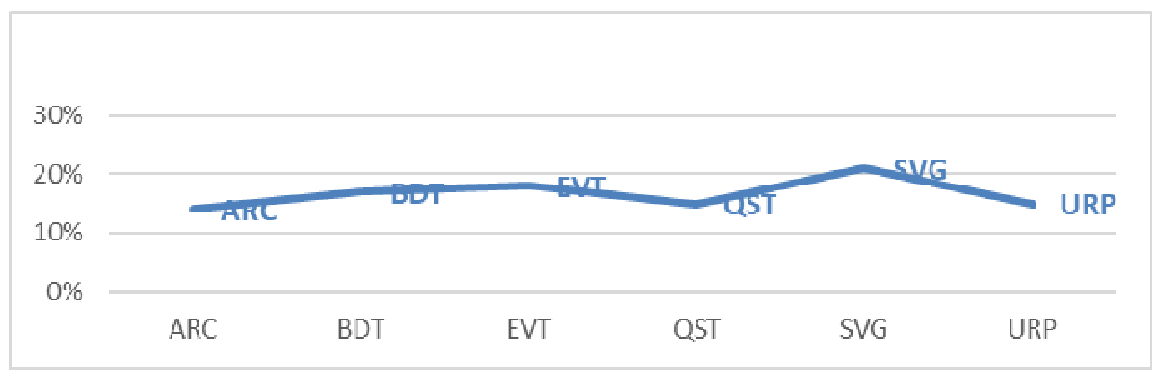

Figure 6: Discipline wise demographic analysis of undergraduates from School Of Environmental Technology (SOET)

Figure 6 above shows the demographic characteristics in terms of discipline from undergraduate students in the School of Environmental Technology (SOET). Analysis of data reveal that students from the department of Surveying and Geoinformatics (SVG) made the most use of library internet with $67(21 \%)$ entries, this was 
closely followed by Environmental Technology (EVT) which recorded 58(18\%) and Building Technology (BDT) which recorded 53(17\%) entries. However, Urban and Regional Planning (URP) and Quantity Surveying (QST) had 48(15\%) respectively while Architecture (ARC) was the least with 45(14\%) entries. This shows that in the School of Environmental Technology, students from Surveying and Geoinformatics are the most users of FUTO library internet.

\subsection{School Of Health Technology (SOHT)}

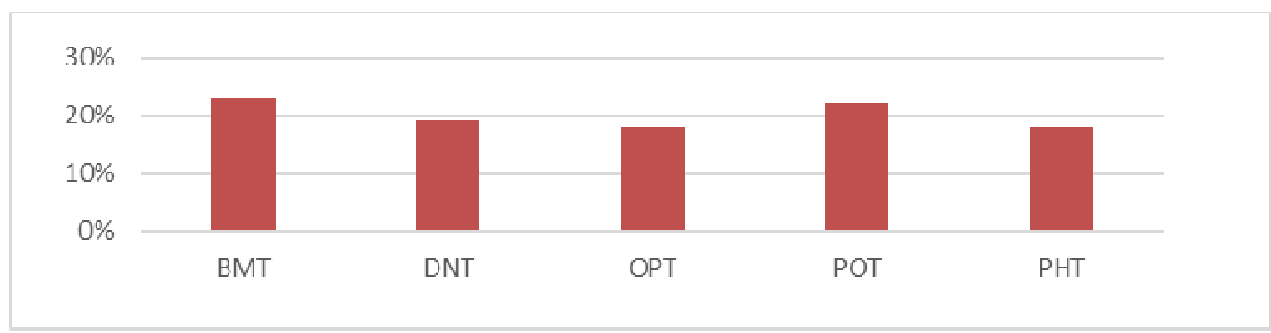

Figure 7: Discipline wise demographic analysis of undergraduates from School of Health Technology (SOHT)

Figure 7 reveals that in the School of Health Technology, undergraduates from department of Biomedical Technology (BMT) made the most use of the library internet $44(23 \%)$ followed by those in the Department of Prosthesis and Orthotics (POT) who had 42(22\%) entries. 36 (19\%) of undergraduates from Dental Technology (DNT) also used the internet while students from Optometry (OPT) and Public Health (PHT) departments were the least in library internet usage with 35 and 34 entries which resulted in $18 \%$ respectively.

\subsection{School Of Physical Sciences (SOPS)}

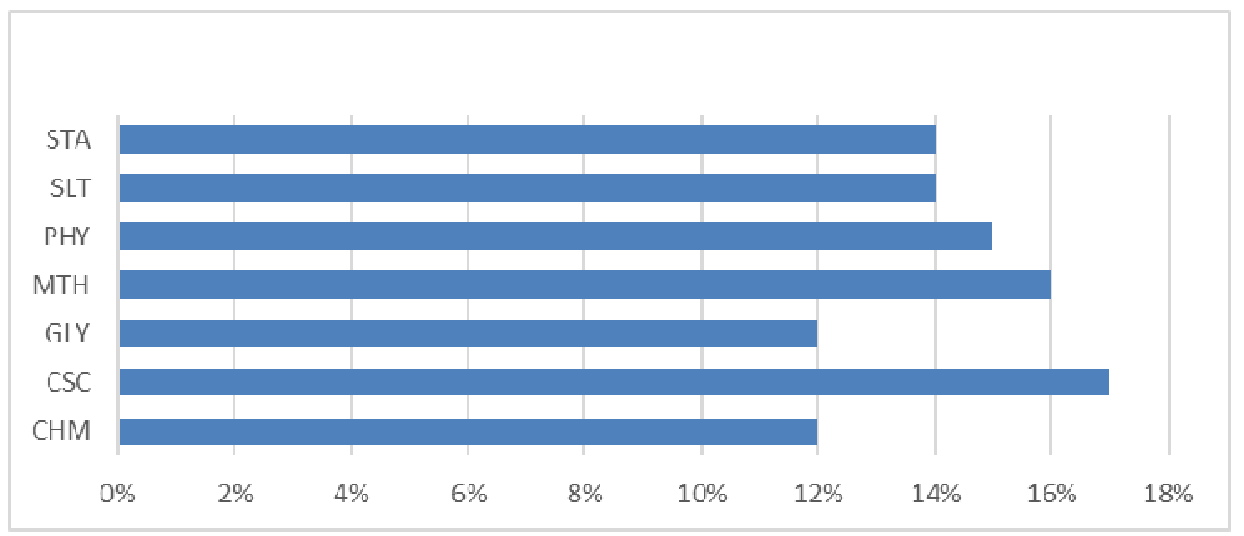

Figure 8: Discipline wise demographic analysis of undergraduates from School of Physical Sciences (SOPS)

Figure 8 shows data from the School of Physical Sciences. The Figure reveals that undergraduate students from Computer Science (CSC) were the most users of the library internet with $83(17 \%)$ entries. This was closely followed by Department of Mathematics (MTH) which revealed 80(16\%) entries. Also 76(15\%) name entries were found for Physics (PHY), Department of Statistics (STA) and Science Laboratory Technology (SLT) revealed 69(14\%) entries respectively while undergraduates from Chemistry (CHM) and Geology (GLY) department recorded 64(12\%) entries respectively. 


\subsection{Summary Of Discipline Wise Demographic Analysis of Undergraduate's Library Internet Usage}

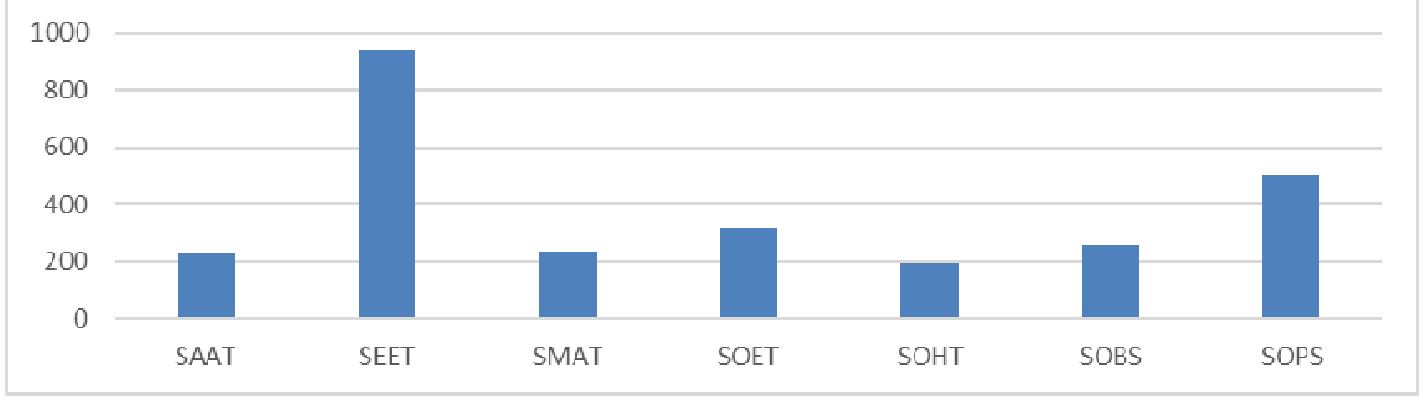

Figure 9: Summary of Discipline wise demographic analysis of undergraduate's library internet usage Figure 9 indicates that 940 (35\%) undergraduates from School of Engineering and Engineering Technology (SEET) made the most use of the library internet. This was followed by 503 (19\%) undergraduates from School of Physical Sciences and 319 (12\%) from School of Environmental Technology. The School of Health had the least entry of $191(7 \%)$ of the total population. From the figure above, it is adduced that students from School of Engineering and Engineering Technology were the most users of the library internet in FUTO.

\subsection{Table 1: Level wise demographic characteristics of undergraduates' library internet usage}

\begin{tabular}{lcc}
\hline Level & Frequency & Percentage \\
\hline 500 & 907 & $34 \%$ \\
400 & 348 & $13 \%$ \\
300 & 417 & $15 \%$ \\
200 & 377 & $14 \%$ \\
100 & 633 & $24 \%$ \\
\hline \hline Total & $\mathbf{2 6 8 2}$ & $\mathbf{1 0 0 \%}$ \\
\hline
\end{tabular}

A cursory look at the table reveals that $907(35 \%)$ of the library internet users were 500 level undergraduate students while $633(24 \%)$ were 100 level students. Also, 417(15\%) were from 300 level while $377(14 \%)$ were from 200 level. The table shows that those who used the internet least within the reporting period was the 400 level students 348(13\%). The table demonstrates that final year (500 level) students use the library internet most.

\section{Discussion of Findings}

The findings of the study show that males were greater in number than females. This finding is not surprising as it is observed that any study seeking gender disparity in FUTO will always find that males are in the greater majority. This is because FUTO is not a conventional university. Its' academic structure hinges on Science, Technology and Engineering. As a result, males dominate most of the courses while the females are few. According to Hango (2013), women are still underrepresented in science, technology, engineering, mathematics and computer science (STEM) fields. Arising from this background, the present study will not justify the assertion that males use the internet more than the females or vice versa. However, work place experience and observations reveal that females spent quality time in the use of library internet in that they focused on their academics more than the males. This connects with the observation made by Castano, Duart and Vinuesa (2015) that women are the gender that use the internet most for interactive learning more than men.

The study found that students from various departments in FUTO use the library internet in several degrees. In the School of Agriculture and Agricultural Technology (SAAT), students from Agricultural Economics (AEC) made most use of the library internet while department of Electrical and Electronics Engineering (EEE) were the most users of library internet in the School of Engineering and Engineering Technology (SEET). Students from Information Management Technology (IMT) and Project Management Technology (PMT) used the internet most in the School of Management Technology (SMAT) while those in Biotechnology (BIO) made the most use of 
library internet in the School of Biological Sciences (SOBS). Furthermore, the study reveal that students from Department of Surveying and Geoinformatics (SVG) were the most library internet users in the School of Environmental Technology (SOET).

Similarly, Biomedical Technology (BMT) students made use of the internet more than their counterparts in the School of Health Technology (SOHT). This contradicts the finding by Dery (2016) that the Dental School had the highest proportion of respondents who used internet more than others in the college of health sciences in University of Ghana. Also, Computer Science (CSC) students used the internet most in School of Physical Sciences (SOPS). This finding validates that of Stone and Collins (2013) who reveal that discipline exerts a much bigger influence on internet usage. On the overall faculty level, the study shows that students from School of Engineering and Engineering Technology (SEET) made most use of the library internet than other Schools. This finding also collaborates that of Stone and Collins (2013) and Duart and Vinuesa (2015) who observe that having high internet usage abilities has a different effect according to the study program in which the student is pursuing his/her degree.

Further findings from the study reveal the demographic characteristics of library internet usage in terms of level. While there was considerable use of the internet by undergraduates in various levels, the study demonstrates that final year (500 level) students use the library internet most. This finding tallies with Okwaraji, et al. (2015) who showed that final year undergraduate students reported more severe internet addiction than those at other levels. Also, this finding is in tune with Bolu-Steve, Oyeyemi, and Amali (2015) who found a significant difference in use of internet and educational levels of University of llorin undergraduate students. The final year class are the "project students" who are usually involved in seminars and research. This may be why they use library and internet resources to a high extent. It is likely that they are at home with information search and retrieval processes having been in the university for quite a while. That is why Bidin, Shasudim, Shariff and Hashim (2011) stated that final years have been exposed to the higher education environment and are better exposed to the internet applications in their academic experiences.

\section{Conclusions and Recommendations}

The FUTO library has the responsibility of providing up to date information resources to satisfy user needs. The library's internet solely aims to provide quick access to varied information resources and also complement traditional services. This study has shown the demographic characteristics of FUTO undergraduates and the differences that exist in library internet usage. The study also demonstrated that some departments made use of the library internet more than others. The reason for this disparity in internet usage may be associated with certain factors which could be related to the ones identified in literature.

Based on the revelations of this study, there is urgent need to ensure optimal use of the internet by all departments and students at various levels. Hence this study recommends that:

1. Embedded librarians who bridge the information gap should wake up to their responsibilities by employing further steps to promote library operations and services. This could be achieved through constant connection and communication with various departments under their watch, continuous marketing and awareness creation of the library's internet facility.

2. Embedded librarians should schedule pep/library talks to students and to lecturers during departmental or faculty board meetings to educate and create awareness on library internet and e-resources as lack of knowledge on library electronic resources/databases is an impediment to usage.

3. Librarians should ensure that undergraduates are closely monitored and assisted in the library while they are online as failure to connect with their information need may be frustrating and could discourage subsequent use of the library internet.

4. Online information search and retrieval methods should be incorporated in the information literacy curriculum and facilitated by librarians for improved use of the library internet

5. Librarians should support and promote the use of library databases and constantly update and provide login details to enable users have unlimited access.

\section{References}

Adepoju, O.E. (2017). Demographic factors affecting ICT utilization by undergraduate students in some selected universities in Nigeria. International Journal of Library and Information Science Studies, 3 (2), 20-33. 
Ajuwon, G.A. \& Popoola, S.O. (2014). Influence of internet accessibility and demographic factors on utilization of web based health information resources by resident doctors in Nigeria. African Journal of Medical Sciences, 43 (Suppl 1), 61-71.

Ani, O. (2010). Internet access and use. The Electronic Library, 28 (4), 555-567. http://dx.doi.org/10.1108/02640471011065373

Anunobi, C.V. \& Mbagwu, F.C. (2009). Determinants of internet use in Imo state, Nigeria. Educational Research and Review, 4 (9), 436-442.

Barllan, J.; Peritz, B.C. \& Yecheskel, W. (2003). A survey on the use of electronic databases and electronic journals accessed through the web by the academic staff of Israeli universities. The Journal of Academic Librarianship, 29 (6), 346-361.

Bidin, Z., Shamsudin, F.M., Sharif, Z. \& Hashim, M.F. (2011). Determinants of students' internet usage for academic purposes. Retrieved at: https://papers.ssrn.com/sol3/papers.cfm?abstract_id=1867902

Bolu-Steve, F. N., Oyeyemi, O. P. \& Amali, I. O. O. (2015). Internet usage and academic performance of undergraduate students in University of Ilorin, Nigeria. Ethiopian Journal of Education and Sciences, $11(1), 39-47$.

Brown, J. S., \& Adler, R. P. (2008). Minds on fire: Open education, the long tail, and learning 2.0. Educause Review, 43 (1) 16-32.

Cabanero-Johnson, P.S. \& Berge, Z. (2009). Digital natives: back to the future of microworlds in a corporate learning organization. The Learning Organization, 16 (4), 290-297. Retrieved at: https://doi.org/10.1108/09696470910960383

Castaño, J.; Duart, J.M. \& Sancho-Vinuesa, T. (2015). Determinants of Internet use for interactive learning: an exploratory study. New Approaches in Educational Research, 4 (1), 24-31

Chaudhari, B.; Menon, P.; Saldanha, D.; Tewari, A. \& Bhattacharya, L. (2015). Internet addiction and its determinants among medical students. Industrial Psychiatry Journal, 24(2), 158-162.

Cox, B. \& Jantti, M.H. (2012). Capturing business intelligence required for targeted marketing, demonstrating value, and driving process improvement. Library and Information Science Research, 34 (4), 308-316. http://dx.doi.org/10.1016/j.1isr.2012.06.002

Dery, S.; Vroom, F.; Godi, A.; Afagbedzi, S. \& Dwomoh, D. (2016). Knowledge and use of information and communication technology by health sciences students of the University of Ghana. Retrieved at https://www.ncbi.nlm.nih.gov/pmc/articles/PMC5044793/

Hango, D. (2013). Gender differences in science, technology, engineering, mathematics and computer science (STEM) programs at university. Retrieved at: https://www.researchgate.net/publication/282877694_Gender_Differences_in_Science_Technology_Engin eering_Mathematics_and_Computer_Science_STEM_Programs_at_University

Hossain, A. \& Rahman, H. (2017). Comparative study of internet usage among University students: a study of the University of Dhaka, Bangladesh. European Scientific Journal, 13 (34), 134 - 150.

Ineme, M.E.; Ineme, K.M.; Akpabio, G.A. \& Osinowo, H. O. (2017). Predictive Roles of Depression and Demographic Factors in Internet Addiction: A Cross-Sectional Study of Students in a Nigerian University. International Journal of Cyber Criminology, 11 (1), 10-23.

Jones, S. Johnson-Yale, C., Millermaier, S. \& Pérez, F.S. (2009), “U.S. college students' Internet use: Race, gender and digital divides. Journal of Computer-Mediated Communication, 14 (2), 244-264. Retrieved at: http://dx.doi.org/10.1111/j.1083-6101.2009.01439.x

Kilic, A.F. \& Guzellar, C.O. (2017). Demographic factors affecting internet using purposes of high school students. Malaysian Online Journal of Educational Technology, 5 (1). Retrieved at: https://files.eric.ed.gov/fulltext/EJ1125130.pdf

Mostafa, S. (2011). Internet access and use among business students of a private university of Bangladesh: A Survey. Annals of Library and Information Studies, 58, 78-85.

Korobili, S; Tilikidou, I. \& Delistavrou, A. (2006). Factors that influence the use of library resources by faculty members. Retrieved from: https://www.researchgate.net/publication/235298166 
Odell K, Korgen K, Schumacher P, Delucchi M. (2000). Internet use among female and male college students. CyberPsychology \& Behaviour, 3 (5), 855-862.

Okiki, O.C and Asiru, S.M .2011. Use of Electronic Information Sources by Postgraduate Students in Nigeria: Influencing Factors. Library Philosophy and Practice, 4-6.

Okwaraji, F. E., Aguwa, E. N., Onyebueke, G. C. \& Shiweobi-Eze, C. (2015). Assessment of internet addiction and depression in a sample of Nigerian university undergraduates. International Neuropsychiatric Disease Journal, 4 (3), 114-122.

Owolabi, E.S. (2013). Socio-demographic factors as determinants of access and use of ICT by staff of university libraries in Oyo State. Library Philosophy and Practice. Retrieved at http://digitalcommons.unl.edu/libphilprac/947

Pew Research Center (2018). Demographies of internet and home broadband usage in the United States of America. Retrieved at: http://www.pewinternet.org/fact-sheet/internet-broadband

Quadri, G. O. (2013). Influence of Demographic factors on Use of Online Library Resources by Undergraduate Students in Two Private Nigerian University Libraries. Library Philosophy and Practice (e-journal), 976. Retrieved: http://digitalcommons.unl.edu/libphilprac/976

Servidio, R. (2014). Exploring the effects of demographic factors, internet usage and personality traits on internet addiction in a sample of Italian university students. Computers in Human Behavior, 35, 85 - 92.

Selwyn, N. (2008). An Investigation of differences in undergraduates academic use of the internet. Active Learning in Higher Education, 9 (1), 11-22.

Stone, G. \& Collins, E. (2013). Library usage and demographic characteristics of undergraduate students in a UK university. Performance Measurement and Metrics, 14 (1), 25-35.

Talwar P, Sabil S, Mustafa MS, Otham MK, Hian CC, Aman S. (2018). Reconnoitering the Influence of Sociodemographic Factors on Internet Addiction. Online Journal of Health Allied Sciences, 17 (1), 8. Retrieved at: https://www.ojhas.org/issue65/2018-1-8.html

Tchombe, T.M.S. (2008) Gender and Psycho-pedagogical implications for cognitive Growth through Access to information and communication Technologies. Bamako Mali: ERNWACA/ROCARE. The American Society for Information Technology 537, 594-566.

Topaloglu, A. O. \& Topaloglu, M. (2015). The study of computer technology and information systems students' problematic internet use levels and predictiveness with the regard to various variables. Procedia - Social and Behavioral Sciences (182), $637-644$.

Ugwulebo, J.E. \& Okoro, S. N. (2016). Impact of internet usage on the academic performance of undergraduates students: a case study of the University of Abuja, Nigeria. International Journal of Scientific \& Engineering Research, 7 (10). Retrieved at: http://www.ijser.org

Wong, S.L.; Ng, S.F, \& Hanafi, A. (2008). Gender differences in the usage and attitudes toward the internet among student teachers in a public Malaysian University. American Journal of Applied Sciences 5 (6), 689697. 